\title{
The prevalence and socio-demographic risk factors of coexistence of stunting, wasting and underweight among children under five years in Bangladesh
}

\author{
Mohammad Rocky Khan Chowdhury \\ University of West London College of Nursing Midwifery and Healthcare \\ Md Shafiur Rahman \\ Hamamatsu University: Tokoha Daigaku - Hamamatsu Campus \\ Baki Billah \\ Monash University \\ Russell Kabir \\ Anglia Ruskin University \\ Nirmala K. P. Perera \\ University of Oxford \\ Manzur Kader ( $\square$ manzur.kader@ki.se ) \\ Karolinska Institutet https://orcid.org/0000-0001-8181-648X
}

\section{Research article}

Keywords: BDHS, Child malnutrition, under 5 children, binomial regression, Bangladesh

Posted Date: February 15th, 2021

DOI: https://doi.org/10.21203/rs.3.rs-234367/v1

License: (c) (i) This work is licensed under a Creative Commons Attribution 4.0 International License.

Read Full License 


\section{Abstract \\ Background}

Childhood malnutrition in all its forms is a significant public health challenge for developing countries like Bangladesh. There is a gap in knowledge of the coexistence of various forms of malnutrition among children under five years (under-5) in Bangladesh. This study aims (i) describe prevalence and risk factors for the coexistence of stunting, wasting and underweight among children under-5 in Bangladesh.

\section{Methods}

This study included 6,610 and 7,357 under-5 children from Bangladesh Demographic Health Surveys (BDHS) 2014 and 2017/18 respectively. Associations between coexistence stunting, wasting and underweight and socio-demographic factors were assessed by the Chi-square test and negative binomial regression.

\section{Results}

The prevalence of coexistence of stunting, wasting and underweight gradually declined from $5.2 \%$ in 2014 to $2.7 \%$ in 2017/18. Children of uneducated mothers ((Adjused incidence rate ratio (aIRR) 5.0, 95\% $\mathrm{Cl} 2.3,11.0$ )); with low birth weights (aIRR 2.7, 95\% $\mathrm{Cl} 1.4,5.1$ ); children of age group 36-47 months (alRR 2.5, 95\% $\mathrm{Cl} 1.5,4.1$ ); and children of underweight mothers (aIRR 1.9, 95\% $\mathrm{Cl} 1.4,2.7$ ) were the most important risk factors. However, maternal educational status was not associated with coexistence of stunting, wasting and underweight among children under-5 in 2014 whereas in 2017/18 it was the most influential risk factor. Moreover, watching television less than once a week increased the risk of coexistence of stunting, wasting and underweight by $54 \%$ (aIRR $1.54,95 \% \mathrm{Cl} 1.0,2.4$ ).

\section{Conclusions}

one out of thirty-five under- 5 children were identified to have coexistence of stunting, wasting and underweight in Bangladesh. The burden of malnutrition was disproportionate among uneducated mother, underweight mother, low birth weight and socio-economically poorest household. Our study indicates that there is a need for multi-level interventions from household level to societal level to reduce consequences of childhood malnutrition.

\section{Background}

Childhood malnutrition in all its forms is a significant public health challenge. Malnutrition, in all its forms contributing to more than half of global deaths among children under five years (under-5), with the majority in low- and middle-income countries [1]. The coexistence of three forms of malnutrition (i.e. 
stunting, wasting and underweight) is prevalent in 124 countries with 41 countries severely affected [2]. Bangladesh currently experiences high malnutrition rates among its under-5 population with $40 \%$ of children affected by one or more forms of malnutrition and attributing to over $50 \%$ of deaths in children under-5 $[3,4]$. Critically, more than $30 \%$ of children under-5 suffer coexistence of multiple forms of malnutrition [5]. Children with the coexistence of stunting, wasting and underweight have a 12-fold elevated risk of mortality compared to children with only one dimension of malnutrition [6]. Further, the degree of cognitive impairment, impairments to thymic development, decreased peripheral lymphocyte count and increased susceptibility to infections are directly related to the severity and co-occurrence of multiple dimensions of malnutrition [7].

Although malnutrition rates in Bangladesh declined since the 1990s, progress to tackle all forms of malnutrition remains unacceptably slow [8]. Risk factors for single malnutrition indicators (i.e. stunting, wasting or underweight) are multifaced ranging from access to nutrients, socio-demographic factors, poverty, access to healthcare and geographical location $[3,9,10,11,12]$. However, determinants of coexistence of stunting, wasting and underweight is not previously explored particularly in Bangladesh to inform context-specific evidence-based prevention strategies. Therefore, this study aims to (i) identify the prevalence and risk factors for the coexistence of stunting, wasting and underweight among children under-5 in Bangladesh.

\section{Methods}

\section{Data source}

Data of non-institutional residing Bangladeshi adults from the Bangladesh Demographic Health Surveys (BDHS) 2014 and 2017/18 were used for this study. The BDHS collects health and nutritional indicators' data using a standard questionnaire with $99 \%$ response rate on average. Details of the survey questionnaire, sample design, data collection procedure can be found in BDHS 2014 and 2017/18 [5,13].

The BDHSs surveys use two-stage stratified sampling techniques to select primary sampling units (PSUs) and households using probability proportional to their size and an equal probability systematic sampling technique, respectively [5,13]. The enumeration areas (clusters) were taken from the 2011 censuses compiled by the Bangladesh Bureau of Statistics and were considered as the PSUs $[5,13]$. Children born from January 2009 or later and aged under five years at the time of the survey were considered eligible for height and weight measurements. A total of 7,886 (BDHS 2014) and 8,759 (BDHS 2017/18) children met the eligibility criteria, and 6,610 (BDHS 2014) and 7,357 (BDHS 2017/18) children complete and credible anthropometric and socio-demographic data (Figure 1).

\section{Outcome variables and operational definitions}

The primary outcome was coexistence of stunting, wasting and underweight among under- 5 children in Bangladesh. A child was considered to be stunted (short stature for age), wasted (dangerously thin) and underweight (underweight for age) if their height-for-age, weight-for-height, and weight-for-age indices 
were $\leq-2$ standard deviations (SDs) of the World Health Organization (WHO) reference population median [14]. Stunting, a cumulative effect of chronic malnutrition indicates the failure to receive adequate nutrition over a long period. Wasting is a form of acute malnutrition resulting from poor dietary intake or frequent infections like diarrhea. Underweight is an indication of overall nutritional health and a composite index of stunting and wasting [15]. Implausible values while estimating child malnutrition was defined based on the WHO 2006 standards flag limits of unitless z-score: stunting: $<-6$ or $>6$; wasting: $<-5$ or $>5$; and underweight: $<-6$ or $>5$ [14]. A child is considered malnourished, if he/she is stunted, if he/she is wasted and if he/she is underweight. For each of the questions/indicators, responses were re-coded dichotomously: $1 \rrbracket$ malnourished (i.e. stunting, wasting and underweight) and $0 \otimes$ normal. Thereafter, the responses of all three malnutrition indicators were added which resulted in a score ranging from 0 to 3 . The scores were again recategorized as 0 for normal, 1 stands for children with single dimension of malnutrition (either stunting, wasting or underweight), 2 for children with co-occurrence of two forms malnutrition (i.e. either stunting and wasting, stunting and underweight or wasting and underweight) and 3 for children with coexistence of stunting, wasting and underweight.

\section{Independent variables}

A selection of socio-demographic variables or risk factors of interest were identified from relevant literature $[3,4,8$,$] . The variables were mother's education (no education, primary, secondary, higher);$ mother's working status (currently not working, currently working); mother's body mass index (underweight, normal, overweight); children's age (0-11 month, 12-23 month, 24-35 month, 36-47 month, 48-59 month); sex of child (male, female); birth order (first, second, third, fourth and above); breastfeeding initiation (within 1 hour, after 1 hour); birth weight (normal/average, small, not weighted); watching television (not at all/do not know, less than once a week, at least once a week); wealth index (poorest, poorer, middle, richer, richest), place of residence (urban, rural).

In low income countries, babies are often born at home without proper measurement of birth weight. Actual weight at birth was reported for less than $50 \%$ cases [15]. Therefore, all DHS in developing countries retrospectively collect information on baby's size at birth based on mother's perception as proxy of birth weight by asking the question "was the newborn very large, larger than average, average, smaller than average or very small?" Approximately $75 \%$ mothers can correctly report their baby's size at birth, therefore mother's recall is a valid proxy measure of birth weight $[16,17,18]$. The wealth index or socioeconomic status was constructed using information about household assets that were collected in BDHSs. The data on household assets included ownership of durable goods (e.g. televisions and bicycles) and dwelling characteristics (e.g. source of drinking water, sanitation facilities, and construction materials). Principal component analysis was performed to assign individual household wealth scores. These weighted values were then summed and rescaled to range from 0-1, and each household was assigned into quintiles: the first quintile: poorest; the second quintile: poorer; the third quintile: middle class; the fourth quintile: richer and the fifth quintile: richest [5].

\section{Statistical analysis}


Descriptive statistics were used to describe socio-demographic characteristics. The prevalence of coexistence of stunting, wasting and underweight was estimated using Chi-square test. Prevalence estimates considered the complex survey design and sampling weights. In all analyses, the significance level was set at $\mathrm{P}<0.05$ (2-tailed). Adjusted models were developed to analyze the appropriate binary value for the adverse nutritional outcome of children under-5 (i.e. coexistence of stunting, wasting and underweight). All independent variables except those were found insignificant in the bivariate analysis (Chi-square test) were simultaneously entered into the negative binomial regression models for adjustment. A negative binomial regression model was used due to unequal dispersion property, i.e. mean $\neq$ variance and for the occurrence of rare cases $(<10 \%)$. The strength of associations was assessed using incidence rate ratios (IRR). 95\% confidence intervals (Cls) were used for significance testing. All statistical analyses were performed using Stata version 14.2 and sample weighting based on the complex design of the BDHSs was considered.

\section{Results}

Approximately $15 \%$ mothers were uneducated, $25 \%$ mothers were currently working and $23 \%$ were underweight. Approximately $40 \%$ children had poor socio-economic status and $68 \%$ were living in a rural area. Approximately, $41 \%$ of children were aged less than 23 months and $52 \%$ were males (Table 1 ).

\section{Prevalence of coexistence of stunting, wasting and underweight}

For the survey year 2014, the prevalence of coexistence of stunting, wasting and underweight was $5 \%$ that declined to $3 \%$ in the survey year $2017 / 18$ (Table 2). In both 2014 and $2017 / 18$ surveys, the prevalence of malnutrition was high in children of underweight mothers ( $8 \% \mathrm{vs} 6 \%$ ), children of uneducated mothers ( $8 \%$ vs $5 \%$ ), children with low birth weight ( $11 \%$ vs $4 \%$ ), and from very poor families (8\% vs $4 \%$ ) (Table 2$)$.

\section{Risk factors}

From 2014 survey, children from socio-economically poorest families ((adjusted IRR (aRR) 2.3, 95\% Cl 1.5, 3.8)); children of age group 36-47 months (aIRR 2.2, 95\% $\mathrm{Cl} 1.5,3.3$ ); with low birth weights (aIRR) 2.1, $95 \% \mathrm{Cl} 1.4,3.1$ ); and children of underweight mothers (aIRR 1.7, 95\% $\mathrm{Cl} 1.4,2.2$ ) had a high risk of coexistence of stunting, wasting and underweight (Table 3). On the other hand, the most influential risk factors of coexistence of stunting, wasting and underweight in the survey 2017/18 were children of uneducated mothers (aIRR 5.0, 95\% Cl 2.3, 11.0); with low birth weights (aIRR) 2.7, 95\% Cl 1.4, 5.1); children of age group 36-47 months (aIRR 2.5, 95\% Cl 1.5, 4.1); and children of underweight mothers (alRR 1.9, 95\% Cl 1.4, 2.7) (Table 3).

Surprisingly, watching television less than once a week increased the risk of coexistence of stunting, wasting and underweight by $54 \%$ (aIRR $1.54,95 \% \mathrm{Cl} 1.0,2.4)$ among children than not exposed to this media (Table 3). 


\section{Discussion}

One of the key findings of this study is approximately $3 \%$ children under-5 experience coexistence of stunting, wasting and underweight which can have a detrimental impact on their short- and long-term health. India reports a very high figure with approximately one in ten children under-5 reporting coexistence of stunting, wasting and underweight [19]. Compared to other poor-income countries like Malawi $(2 \%)$ and Ethiopia $(4 \%)[20,21]$ the prevalence of coexistence of stunting, wasting and underweight is high in Bangladesh. Limited resources at the National Nutrition Services (NNS) in Bangladesh may result in limited coverage and quality of interventions. Frequent changes in leadership, coordination, capacity, and workload-related challenges faced by the NNS have hampered the implementation of nutrition interventions [22]. However, we observed the coexistence of stunting, wasting and underweight among children declined 2 percentage point in 2017/18 from 5\% in 2014 indicating that current interventions might be effective. Therefore, leadership, stability and resources at the NNS can provide further coverage of high-quality interventions to further decrease the coexistence of malnutrition in children under-5.

In recent survey, we found the risk of coexistence of stunting, wasting and underweight increased by $402 \%$ in children of uneducated mothers which was insignificant in 2014 survey. Lack of maternal education was not assessed most influential risk factors of child malnutrition in previous studies in Bangladesh and other developing countries $[8,23,24,25]$. Current evidence also showed that three out of fifty children of uneducated mothers were suffering from coexistence of stunting, wasting and underweight as children of underweighted mothers did. Parallel state of poor maternal educational and socio-economic status in households might affect children with critical nutritional hazard due to knowledge gap and inability to provide appropriate diet [26]. Low birth weight was a risk factor for the coexistence of stunting, wasting and underweight and our results concur with Ramakrishnan (2004) [27]. We found the relative risk of coexistence of three forms of malnutrition increased by $165 \%$ in children with low birth weight compared to normal weight. Children with low birth weight experience growth failure during early childhood which may increase the risk of long-term complications like diarrheal and lower respiratory infections, sleep apnea, jaundice, anemia, chronic lung disorders, fatigue and loss of appetite [28]. Children of older age group (36-47 months) had 2.5 times higher risk of coexistence of three forms of malnutrition than youngest children (less than 1 year). Das and Gulshan (2017) found older children had high risk of stunting ((odds ratio (OR): 1.5)) and lower risk of wasting in Bangladesh [29]. The current estimated risk of the coexistence of three forms of malnutrition among older children was higher compared to previous study finding. After second year of life, children in Bangladesh tend to have the same diet as the family, along with breast milk; although they are often allowed to eat food themselves, they do not always have access to adequate amounts of solid food, and this might contribute to their poor nutritional status [30]. Also, the coexistence of three forms of malnutrition increased by $95 \%$ for those born to underweight mothers. Likely because mothers are underweight due to food insecurity, poverty and micronutrient deficiencies [31]. Poorer socio-economic status [3] is another risk factor contributes coexistence of stunting, wasting and underweight and our findings concur demonstrating the complex nature of this public health issue. Investing in maternal and child healthcare system, increased 
participation of underprivileged people in income generating activities can improve the nutritional status of children. Further, improving women's education can contribute towards increasing family income, access to a better quality of diet consequently improving children's health [32]. Increasing education opportunities for females, especially in rural areas is recommended [8].

Surprisingly, watching television less than once a week increased the risk of coexistence of stunting, wasting and underweight by $54 \%$ among children than households not exposed to this media. This finding was not consistent with a study conducted in Bangladesh [8,33]. Inconsistent contents of food advertisements regarding dietary recommendations and poorer understanding of nutrition from food advertisements in television might cause adverse nutritional outcomes, indicating need of attention of the policy makers to the matter $[34,35]$.

Use of multiple nationally representative household survey data points with a high response rate was a strength of this study. The survey questions were validated and established. Although suitable statistical tools like Negative Binomial Regression was used to assess the risk factors, the cross-sectional nature of the data was not sufficient to establish a causal relationship between risk factors and the dependent variables. Further, data on potential confounders like diet, food insecurity and parents smoking behavior were unavailable. The BDHS data were collected retrospectively and self-reported, underreporting, information bias, recall bias might be possible.

\section{Conclusion}

The burden of malnutrition among children under five years in Bangladesh was disproportionate among children of mother with no education, children with low birth weight, children of older age group (3647 months), children of underweight mothers, and socio-economically poorest families. Our study will provide helpful guidelines for intervention development from household level to societal level to reduce short- and long-term health consequences of childhood malnutrition. Level of mother's education, underweight mother, low birthweight, and poorest socio-economic status should be the focus of evidencebased interventions. Effective and systematic coordination of the implementation of interventions requires between different nutritional programs and policies to support such strategies.

\section{Abbreviations}

BDHS: Bangladesh Demographic Health Survey, BMl: Body Mass Index, Cl: Confidence Interval, IRR: Incidence Rate Ratio, NNS: National Nutrition Services, PSU: Primary Sampling Units, WHO: World Health Organization.

\section{Declarations}

Acknowledgement: Not Applicable.

Ethics approval and consent to participate: 
Since this study was based on secondary analysis of the data obtained from Bangladesh Demographic and Health Survey (BDHSs), 2007-2018, no ethical approval was needed for this study. The BDHS surveys were reviewed and approved by the ICF Macro Institutional Review Board (USA) and complies with all the requirements of 45 CFR 46 - "Protection of Human Subjects". The BDHS was also reviewed and approved by the National Research Ethics Committee of the Bangladesh Medical Research Council (Dhaka, Bangladesh). The survey ensured international ethical standards of confidentiality, anonymity, and informed consent. However, request to access datasets from measure DHS website is made, and the websites has allowed the same before analyses is made.

Consent for publication: Not applicable.

Availability of data and materials: The data underlying the results presented in the study are publicly accessible and available from DHS website (https://dhsprogram.com/data/available-datasets.cfm). Name of the dataset is Bangladesh Demographic and Health Survey (BDHS).

Competing interests: The authors declare that they have no competing interests.

Funding: This research received no specific grant from any institutions.

Authors' contributions: MRKC conceptualized the basic idea for the study, performed the statistical analysis together with MSR and RK. MRKC and MK prepared data for analysis and the first draft of the manuscript. BB and NKPP critically revised the manuscript for intellectual content. All authors have reviewed and approved the final manuscript.

\section{Author details:}

1 College of Nursing, Midwifery and Healthcare, University of West London, London, UK

2 Research Center for Child Mental Development, Hamamatsu University School of Medicine, Japan

3 Department of Epidemiology and Preventive Medicine, School of Public Health and Preventive Medicine, Monash University, Melbourne, Australia

4 School of Allied Health, Faculty of Health, Education, Medicine and Social Care, Anglia Ruskin University, Chelmsford, UK

5 Nuffield Department of Orthopaedics, Rheumatology, and Musculoskeletal Sciences, University of Oxford, UK

6 Unit of Physiotherapy, Department of Health, Medicine and Caring Sciences (HMV), 
7 Institute of Environmental Medicine, Karolinska Institutet, Stockholm, Sweden

\section{References}

1. Swaminathan S, Rasaily R, Bansal PG, Chakma JK, Dwivedi S, Gonmei Z, et al. The burden of child and maternal malnutrition and trends in its indicators in the states of India: The Global Burden of Disease Study 1990-2017. Lancet Child Adolesc Health. 2019;3(12):855-870.

2. Development Initiatives. 2018 Global Nutrition Report: Shining a light to spur action on nutrition. 2018. https://globalnutritionreport.org/reports/global-nutrition-report-2018/ Accessed 11 Dec 2019.

3. Chowdhury MR, Rahman MS, Khan MM, Mondal MN, Rahman M, Billah B. Risk factors for child malnutrition in Bangladesh: a multilevel analysis of a nationwide population-based survey. Journal of Pediatrics. 2016:172:194-201.

4. Chowdhury MRK, Khan HTA, Mondal MNI. Kabir R. Socio-demographic risk factors for severe malnutrition in children aged under five among various birth cohorts in Bangladesh. Journal of Biosocial Science. 2020;1-16.

5. Bangladesh Demographic and Health Survey 2017-18. National Institute of Population Research and Training, 486 Mitra and Associates and Macro International, Dhaka, Bangladesh. 2019. https://www.dhsprogram.com/pubs/pdf/PR104/PR104.pdf Accessed 25 Oct 2020.

6. McDonald CM, Olofin I, Flaxman S, Fawzi WW, Spiegelman D, Caulfield L.E, et al. The effect of multiple anthropometric deficits on child mortality: meta-analysis of individual data in 10 prospective studies from developing countries. The American Journal of Clinical Nutrition. 2013;97(4):896-901.

7. Khattak UK, Iqbal SP. Ghazanfar H. The role of parents' literacy in malnutrition of children under the age of 5 years in a semi-urban community of Pakistan: a case-control study. Cureus. 2017;9(6):1316.

8. Islam MR, Rahman MS, Rahman MM, Nomura S, de Silva A, Lanerolle P, et al. Reducing childhood malnutrition in Bangladesh: the importance of addressing socioeconomic inequalities. Public Health Nutrition. 2019;23(1):72-82.

9. Kandala NB, Madungu TP, Emina JB, Nzita, KP, Cappuccio FP. Malnutrition among children under the age of five in the Democratic Republic of Congo (DRC): does geographic location matter? BMC Public Health. 2011;11:261

10. Aguayo VM, Badgaiyan N, Paintal K. Determinants of child stunting in the Royal Kingdom of Bhutan: an in-depth analysis of nationally representative data. Maternal and Child Nutrition. 2015;11:333345

11. Madhusudhan K, Shireesha ARPK, Ushashree GV. Study of risk factors of severe acute malnutrition (SAM) in children 6 months to 5 years of age and evaluation of effect of micronutrient supplementation (WHO protocol) on serum zinc and magnesium levels: a case control study. International Journal of Contemporary Pediatrics. 2017;4(4):8. 
12. Walson JL, Berkley JA. The impact of malnutrition on childhood infections. Current Opinion in Infectious Diseases. 2018;31(3):231.

13. Bangladesh Demographic and Health Survey 2014. National Institute of Population Research and Training, 486 Mitra and Associates and Macro International, Dhaka, Bangladesh. 2016. https://dhsprogram.com/pubs/pdf/FR311/FR311.pdf Accessed 25 Dec 2019.

14. World Health Organization. WHO child growth standards: length/height-for-age, weight-for-age, weight-for-length, weight-for-height and body mass index-for-age: methods and development. Geneva, Switzerland. 2006. https://www.who.int/childgrowth/standards/Technical_report.pdf?ua=1 Accessed 30 August 2020

15. Rahman MS, Howlader T, Masud MS, Rahman ML. Association of low-birth weight with malnutrition in children under five years in Bangladesh: Do mother's education, socio-economic status, and birth interval matter? PLoS ONE. 2016;11(6):e0157814.

16. Sreeramareddy C, Shidhaye R and Sathiakumar N. Association between biomass fuel use and maternal report of child size at birth-an analysis of 2005-06 India demographic health survey data. BMC Public Health. 2011;11:403-410.

17. Khanal V, Sauer K, Karkee R, Zhao Y. Factors associated with small size at birth in Nepal: further analysis of Nepal Demographic and Health Survey 2011. BMC Pregnancy and Childbirth 2014;14:32.

18. Haque SMR, Tisha S, Huq N. Poor birth size a badge of low birth weight accompanying less antenatal care in Bangladesh with substantial divisional variation: Evidence from BDHS-2011. Public Health Research 2015;5:184-191.

19. Boregowda GS, Soni GP, Jain K, Agrawal S. Assessment of under nutrition using Composite Index of Anthropometric Failure (CIAF) amongst toddlers residing in urban slums of Raipur city, Chhattisgarh, India. Journal of Clinical and Diagnostic Research. 2015;9(7):LC04-LC064.

20. Ziba M, Kalimbira AA, Kalumikiza Z. Estimated burden of aggregate anthropometric failure among Malawian children. South African Journal of Clinical Nutrition 2018;31(2):43-46.

21. Workneh KG, Workie DL. Exploring the association of anthropometric indicators for under-five children in Ethiopia. BMC Public Health. 2018;19:764.

22. Saha KK, Billah M, Menon P, Arifeen SE. Mbuya NVN. Bangladesh National Nutrition Services. Assessment of Implementation Status, A World Bank study. 2015. https://elibrary.worldbank.org/doi/abs/10.1596/978-1-4648-0640-7 Accessed 2 August 2020.

23. Bhattarai S, Bhusal CK. Prevalence and associated factors of malnutrition among school going adolescents of Dang district, Nepal. AIMS Public Health. 2019;6(3):291-306.

24. Yirga AA, Mwambi HG, Ayele DG, Melesse SF. Factors affecting child malnutrition in Ethiopia. Afr Health Sci. 2019;19(2):1897-1909.

25. Budhathoki SS, Bhandari A, Gurung R. Gurung A, Ashish KC.Stunting Among Under 5-Year-Olds in Nepal: Trends and Risk Factors. Matern Child Health J. 2020;24:39-47.

26. Makoka D. The Impact of maternal education on child nutrition: Evidence from Malawi, Tanzania, and Zimbabwe. ICF International Calverton, Maryland, USA. DHS working papers. 2013. 
https://dhsprogram.com/pubs/pdf/WP84/WP84.pdf Accessed 2 January 2021.

27. Ramakrishnan U. Nutrition and low birthweight: from research to practice. Am J Clin Nutr. 2004;79:17-21.

28. Rahman MS, Howlader T, Masud MS, Rahman ML. Association of low-birth weight with malnutrition in children under five years in Bangladesh: Do mother's education, socio-economic status, and birth interval matter? PLoS ONE. 2016;11(6):e0157814.

29. Das S, Gulshan J. Different forms of malnutrition among under five children in Bangladesh: a cross sectional study on prevalence and determinants. BMC Nutr. 2017;3:1.

30. Hong R, Banta JE, Betancourt JA. Relationship between household wealth inequality and chronic childhood under-nutrition in Bangladesh. International Journal of Equity Health. 2006;5:15.

31. Sinha PRN, Garg DBS. Epidemiological correlates of nutritional anemia among children (6-35 months) in rural Wardha, Central India. Indian J Med Sci. 2019;62(2):45-54.

32. Islam MM, Alam M, Tariquzaman M, Kabir MA, Pervin R, Begum M, Khan MM. Predictors of the number of under-five malnourished children in Bangladesh: application of the generalized Poisson regression model. BMC Public Health. 2013;13:11.

33. Wali N, Agho KE, Renzaho AMN. Factors associated with stunting among children under 5 years in five South Asian countries (2014-2018): Analysis of Demographic Health Surveys. Nutrients 2020; 12:3875.

34. Miller SA, Taveras EM, Rifas-Shiman SL, Gillman MW. Association between television viewing and poor diet quality in young children. Int J Pediatr Obes. 2008; 3(3):168-176

35. Harrison K, Marske AL. Nutritional content of foods advertised during the television programs children watch most. Am J Public Health. 2005; 95:1568-1574.

\section{Tables}

Table 1 Background characteristics of the children 


\begin{tabular}{|c|c|c|c|c|}
\hline \multirow[t]{2}{*}{ Factors } & \multicolumn{2}{|c|}{ Survey year 2014} & \multicolumn{2}{|c|}{ Survey year 2017/2018 } \\
\hline & Frequency & (\%) & Frequency & $(\%)$ \\
\hline \multicolumn{5}{|l|}{ Mother's education } \\
\hline No education & 1,010 & 15.3 & 521 & 7.1 \\
\hline Primary & 1,823 & 27.6 & 2,098 & 28.5 \\
\hline Secondary & 3,067 & 46.4 & 3,498 & 47.5 \\
\hline Higher & 710 & 10.7 & 1,240 & 16.9 \\
\hline \multicolumn{5}{|l|}{ Mother's working status } \\
\hline Currently not working & 4,937 & 74.7 & 4,375 & 59.5 \\
\hline Currently working & 1,673 & 25.3 & 2,982 & 40.5 \\
\hline \multicolumn{5}{|l|}{ Mother's BMI } \\
\hline Underweight & 1,506 & 22.8 & 1,108 & 15.0 \\
\hline Normal & 3,825 & 57.9 & 4,339 & 59.0 \\
\hline Overweight & 1,279 & 19.3 & 1,910 & 26.0 \\
\hline \multicolumn{5}{|c|}{ Children's age (in month) } \\
\hline $0-11$ & 1,335 & 20.2 & 1,694 & 23.1 \\
\hline $12-23$ & 1,392 & 21.1 & 1,525 & 20.7 \\
\hline $24-35$ & 1,334 & 20.2 & 1,404 & 19.1 \\
\hline $36-47$ & 1,280 & 19.4 & 1,311 & 17.8 \\
\hline $48-59$ & 1,269 & 19.2 & 1,423 & 19.3 \\
\hline \multicolumn{5}{|l|}{ Sex of child } \\
\hline Male & 3,413 & 51.6 & 3,858 & 52.4 \\
\hline Female & 3,197 & 48.4 & 3,499 & 47.6 \\
\hline \multicolumn{5}{|l|}{ Birth order } \\
\hline First & 2,525 & 38.2 & 2,727 & 37.1 \\
\hline Second & 1,998 & 30.2 & 2,431 & 33.0 \\
\hline Third & 1,057 & 16.0 & 1,261 & 17.1 \\
\hline Fourth and above & 1,030 & 15.6 & 938 & 12.8 \\
\hline Breastfeeding initiatio & & & & \\
\hline
\end{tabular}




\begin{tabular}{|lllll|}
\hline Within 1 hour & 1,990 & 30.1 & 2,683 & 36.5 \\
\hline After 1 hour & 4,620 & 69.9 & 4,674 & 63.5 \\
\hline Size of child at birth A, B & & & & \\
\hline Normal/average & 3,812 & 93.9 & 1,784 & 38.6 \\
\hline Small & 248 & 6.1 & 325 & 7.0 \\
\hline Not weighted & & & 2,518 & 54.4 \\
\hline Television watching & & & & \\
\hline Not at all/do not know & 2,707 & 40.9 & 2,783 & 37.8 \\
\hline Less than once a week & 598 & 9.1 & 658 & 9.0 \\
\hline At least once a week & 3,305 & 50.0 & 3,916 & 53.2 \\
\hline Wealth index c & & & & \\
\hline Poorest & 1,417 & 21.4 & 1,621 & 22.0 \\
\hline Poorer & 1,231 & 18.6 & 1,476 & 20.1 \\
\hline Middle & 1,308 & 19.8 & 1,325 & 18.0 \\
\hline Richer & 1,366 & 20.7 & 1,479 & 20.1 \\
\hline Richest & 1,288 & 19.5 & 1,456 & 19.8 \\
\hline Place of residence & & & & \\
\hline Urban & 2,107 & 31.9 & 2,520 & 34.3 \\
\hline Rural & 4,503 & 68.1 & 4,837 & 65.7 \\
\hline Total & 6,610 & 100.0 & 7,357 & 100.0 \\
\hline
\end{tabular}

A, $n=4,060$ in BDHS 2014 and $n=4,627$ in BDHS 2017/18

$B$, children less than $2500 \mathrm{~g}$ are small

C, an aggregated index based on household assets

Table 2 Prevalence of coexistence of stunting, wasting and underweight among children under-5 


\begin{tabular}{|c|c|c|c|c|c|c|}
\hline \multirow[t]{2}{*}{ Factors } & \multicolumn{3}{|c|}{ Survey year 2014} & \multicolumn{3}{|c|}{ Survey year 2017/18 } \\
\hline & Number & $\begin{array}{l}\text { Prevalence } \\
(95 \% \mathrm{Cl})\end{array}$ & $\begin{array}{l}P \\
\text { values }\end{array}$ & Number & $\begin{array}{l}\text { Prevalence } \\
(95 \% \mathrm{Cl})\end{array}$ & $\begin{array}{l}P \\
\text { values }\end{array}$ \\
\hline \multicolumn{7}{|l|}{ Mother's education } \\
\hline No education & 84 & $7.8(5.9,10.2)$ & 0.0007 & 28 & $5.0(3.3,7.4)$ & $<0.001$ \\
\hline Primary & 120 & $5.6(4.4,7.0)$ & & 73 & $3.6(2.8,4.6)$ & \\
\hline Secondary & 143 & $4.5(3.7,5.5)$ & & 96 & $2.6(2.1,3.2)$ & \\
\hline Higher & 21 & $3.1(1.9,5.1)$ & & 9 & $0.7(0.4,1.5)$ & \\
\hline \multicolumn{7}{|l|}{$\begin{array}{l}\text { Mother's working } \\
\text { status }\end{array}$} \\
\hline $\begin{array}{l}\text { Currently not } \\
\text { working }\end{array}$ & 246 & $4.6(3.9,5.4)$ & 0.001 & 106 & $2.3(1.9,2.9)$ & 0.012 \\
\hline Currently working & 122 & $7.0(5.5,8.9)$ & & 100 & $3.3(2.7,4.1)$ & \\
\hline \multicolumn{7}{|l|}{ Mother's BMI } \\
\hline Underweight & 144 & $8.4(6.8,10.4)$ & $<0.001$ & 62 & $5.8(4.5,7.6)$ & $<0.001$ \\
\hline Normal & 190 & $5.0(4.1,6.0)$ & & 112 & $2.5(2.0,3.0)$ & \\
\hline Overweight & 34 & $2.2(1.5,3.2)$ & & 32 & $1.7(1.1,2.5)$ & \\
\hline \multicolumn{7}{|l|}{$\begin{array}{l}\text { Children's age (in } \\
\text { month) }\end{array}$} \\
\hline $0-11$ & 40 & $2.8(2.0,4.1)$ & 0.003 & 42 & $3.0(2.2,4.1)$ & 0.009 \\
\hline $12-23$ & 91 & $6.1(4.6,8.1)$ & & 47 & $3.1(2.3,4.3)$ & \\
\hline $24-35$ & 72 & $5.1(3.9,6.7)$ & & 47 & $3.5(2.6,4.8)$ & \\
\hline $36-47$ & 87 & $6.2(4.9,7.9)$ & & 46 & $2.9(2.2,4.0)$ & \\
\hline $48-59$ & 78 & $5.8(4.4,7.6)$ & & 24. & $1.4(0.9,2.2)$ & \\
\hline \multicolumn{7}{|l|}{ Sex of child } \\
\hline Male & 206 & $5.3(4.4,6.4)$ & 0.748 & 117 & $3.0(2.5,3.6)$ & 0.199 \\
\hline Female & 162 & $5.1(4.2,6.1)$ & & 89 & $2.5(1.9,3.1)$ & \\
\hline \multicolumn{7}{|l|}{ Birth order } \\
\hline First & 123 & $4.4(3.5,5.6)$ & 0.018 & 38 & $3.6(2.5,5.2)$ & 0.313 \\
\hline Second & 96 & $4.8(3.7,6.2)$ & & 31 & $2.5(1.7,3.6)$ & \\
\hline Third & 67 & $5.7(4.2,7.5)$ & & 61 & $2.4(1.9,3.1)$ & \\
\hline
\end{tabular}




\begin{tabular}{|c|c|c|c|c|c|c|}
\hline Fourth and above & 82 & $7.5(5.7,9.7)$ & & 76 & $2.8(2.2,3.7)$ & \\
\hline \multicolumn{7}{|l|}{$\begin{array}{l}\text { Breastfeeding } \\
\text { initiation }\end{array}$} \\
\hline Within 1 hour & 112 & $5.6(4.3,7.2)$ & 0.459 & 132 & $2.7(2.3,3.2)$ & 0.741 \\
\hline After 1 hour & 256 & $5.0(4.3,5.9)$ & & 74 & $2.8(2.2,3.6)$ & \\
\hline \multicolumn{7}{|l|}{$\begin{array}{l}\text { Size of child at birth } \\
\text { A }\end{array}$} \\
\hline Normal/average & 174 & $4.3(3.5,5.2)$ & 0.0001 & 26 & $1.5(1.0,2.3)$ & 0.002 \\
\hline Small & 29 & $10.8(6.9,16.5)$ & & 14 & $4.1(2.3,7.4)$ & \\
\hline Not weighted & & & & 77 & $3.1(2.4,3.9)$ & \\
\hline \multicolumn{7}{|l|}{ Television watching } \\
\hline $\begin{array}{l}\text { Not at all/do not } \\
\text { know }\end{array}$ & 191 & $6.6(5.4,8.0)$ & 0.001 & 88 & $3.0(2.4,3.7)$ & 0.006 \\
\hline $\begin{array}{l}\text { Less than once a } \\
\text { week }\end{array}$ & 34 & $4.8(3.2,7.2)$ & & 29 & $4.5(3.0,6.5)$ & \\
\hline At least once a week & 143 & $4.1(3.4,5.0)$ & & 89 & $2.3(1.8,2.9)$ & \\
\hline \multicolumn{7}{|l|}{ Wealth index ${ }^{B}$} \\
\hline Poorest & 132 & $8.3(6.8,10.2)$ & $<0.001$ & 61 & $4.0(3.1,5.1)$ & 0.0003 \\
\hline Poorer & 82 & $6.2(4.7,8.1)$ & & 53 & $3.2(2.4,4.3)$ & \\
\hline Middle & 62 & $3.8(2.8,5.3)$ & & 42 & $2.9(2.1,4.0)$ & \\
\hline Richer & 58 & $4.3(3.2,5.8)$ & & 32 & $2.2(1.5,3.3)$ & \\
\hline Richest & 34 & $2.9(2.0,4.2)$ & & 18 & $1.1(0.7,1.9)$ & \\
\hline \multicolumn{7}{|l|}{ Place of residence } \\
\hline Urban & 95 & $4.5(3.5,5.8)$ & 0.238 & 62 & $2.4(1.9,3.1)$ & 0.293 \\
\hline Rural & 273 & $5.4(4.6,6.5)$ & & 144 & $2.9(2.4,3.4)$ & \\
\hline Total & 368 & $5.2(4.5,6.0)$ & & 206 & $2.7(2.4,3.2)$ & \\
\hline
\end{tabular}

A, children less than $2500 \mathrm{~g}$ are small

$B$, an aggregated index based on household assets

Table 3 Risk factors of coexistence of stunting, wasting and underweight among children under-5 


\begin{tabular}{|c|c|c|c|c|}
\hline \multirow[t]{2}{*}{ Factors } & \multicolumn{2}{|l|}{ Survey year 2014} & \multicolumn{2}{|l|}{ Survey year 2017/18 } \\
\hline & Adjusted IRR (95\% Cl) & $P$ values & Adjusted IRR (95\% Cl) & $P$ values \\
\hline \multicolumn{5}{|l|}{ Mother's education A } \\
\hline No education & $1.25(0.73,2.15)$ & 0.424 & $5.02(2.29,11.03)$ & $<0.001$ \\
\hline Primary & $1.17(0.70,1.94)$ & 0.548 & $3.32(1.61,6.85)$ & 0.001 \\
\hline Secondary & $1.11(0.69,1.79)$ & 0.664 & $2.97(1.48,5.98)$ & 0.002 \\
\hline Higher & 1.00 & & 1.00 & \\
\hline \multicolumn{5}{|c|}{ Mother's working status A } \\
\hline Currently not working & 1.00 & & 1.00 & \\
\hline Currently working & $1.29(1.03,1.61)$ & 0.025 & $1.12(0.84,1.48)$ & 0.446 \\
\hline \multicolumn{5}{|l|}{ Mother's BMI A } \\
\hline Underweight & $1.73(1.38,2.16)$ & $<0.001$ & $1.95(1.42,2.67)$ & $<0.001$ \\
\hline Normal & 1.00 & & 1.00 & \\
\hline Overweight & $0.65(0.44,0.94)$ & 0.023 & $0.75(0.50,1.12)$ & 0.162 \\
\hline \multicolumn{5}{|c|}{ Children's age (in month) A } \\
\hline $0-11$ & 1.00 & & 1.00 & \\
\hline $12-23$ & $2.05(1.42,2.98)$ & $<0.001$ & $2.01(1.22,3.29)$ & 0.006 \\
\hline $24-35$ & $1.74(1.18,2.56)$ & 0.005 & $2.36(1.44,3.86)$ & 0.001 \\
\hline $36-47$ & $2.24(1.54,3.27)$ & $<0.001$ & $2.46(1.50,4.05)$ & 0.000 \\
\hline $48-59$ & $1.95(1.33,2.87)$ & 0.001 & $2.03(1.22,3.37)$ & 0.006 \\
\hline \multicolumn{5}{|l|}{ Birth order $A$} \\
\hline First & 1.00 & & & \\
\hline Second & $0.98(0.75,1.29)$ & 0.892 & & \\
\hline Third & $1.17(0.86,1.59)$ & 0.317 & & \\
\hline Fourth and above & $1.25(0.91,1.71)$ & 0.160 & & \\
\hline \multicolumn{5}{|l|}{ Size of child at birth B, C } \\
\hline Normal/average & 1.00 & & 1.00 & \\
\hline Small & $2.19(1.48,3.27)$ & $<0.001$ & $2.65(1.38,5.10)$ & 0.004 \\
\hline
\end{tabular}




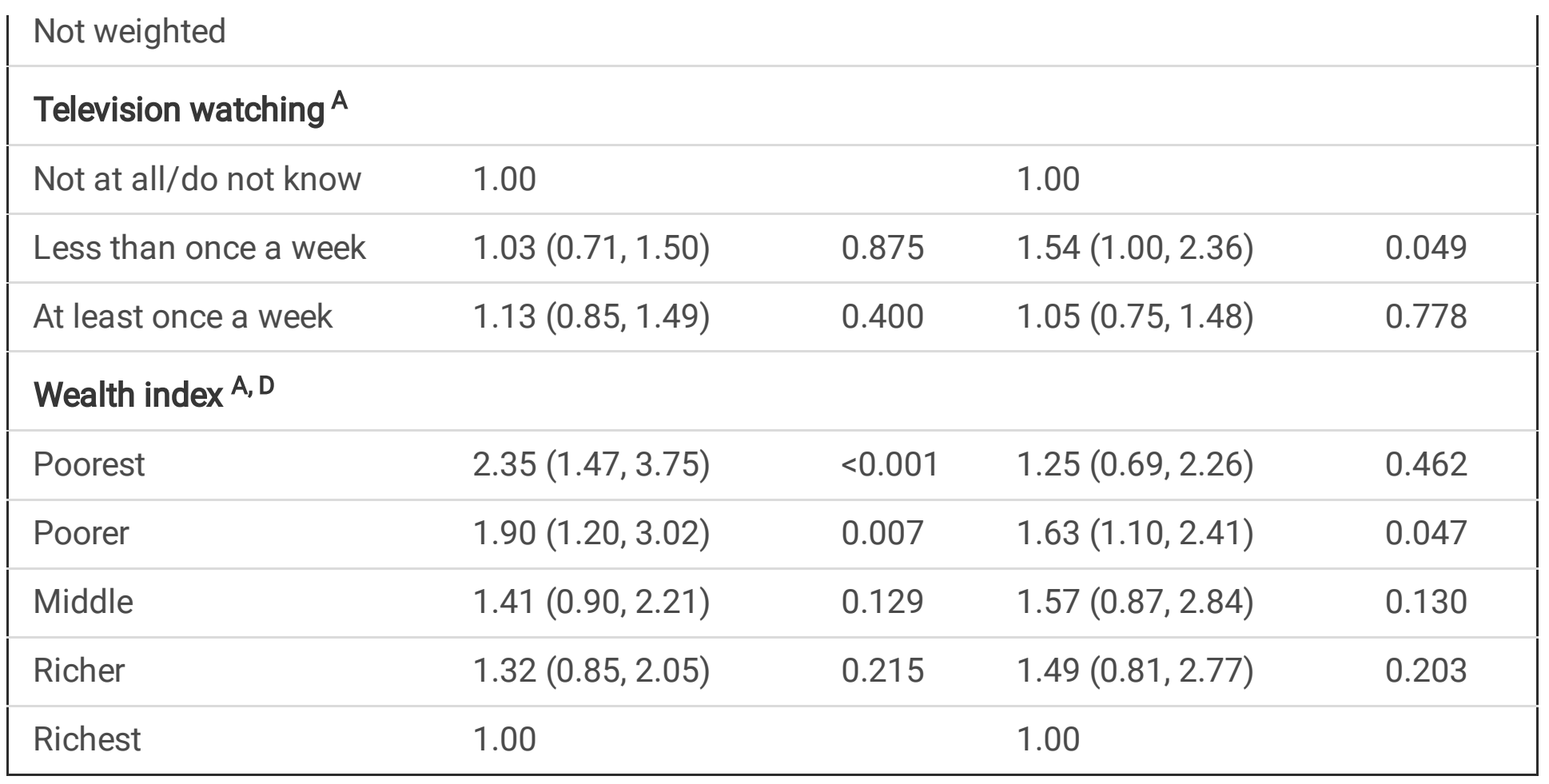
A, adjusting all variables including child age and sex in the regression analysis except size of child at birth
B, simultaneously adjusting all variables including child age and sex in the regression analysis
C, children less than $2500 \mathrm{~g}$ are small
D, an aggregated index based on household assets

\section{Figures}






Figure 1

Schematic presentation of sample size selection 